\title{
A RFBSE model for capturing engineers' useful knowledge and experience during the design process
}

\author{
Hao Qin ${ }^{\mathrm{a}}$, Hongwei Wang ${ }^{\mathrm{a}}$, Aylmer Johnson ${ }^{\mathrm{b}}$ \\ a. School of Engineering, University of Portsmouth, Anglesea Road, Portsmouth PO1 3DJ, UK \\ b. Department of Engineering, University of Cambridge, Trumpington Street, Cambridge CB2 1TL \\ * Corresponding Author: Tel: (+44) 02392842569. E-mail address: hongwei.wang@port.ac.uk
}

\begin{abstract}
Reuse of designers' knowledge and experience of solving problems during the engineering design process holds the key to increase efficiency of decision making in future projects. An important part of this useful knowledge and experience is the interpretation of data and information about design objects and processes as well as the generation of new information for decision-making. However, previous studies on knowledge representation models have mainly focused on developing a structure to describe the knowledge about design objects and design processes while a systematic method that can effectively integrate knowledge about design objects and knowledge about problem-solving strategies is still missing. To fill this gap, a RFBSE knowledge representation model for capturing useful design knowledge and experience for future reuse is developed and evaluated in this study. This paper describes the key elements of this model, explains the rationale of using particular elements, and discusses the evaluation of the model using an engineering design example.
\end{abstract}

Keywords: Knowledge capture, knowledge representation, knowledge model, engineering design, knowledge reuse 


\section{Introduction}

During the design of an artefact, a large amount of design data and information are generated and exchanged during the design process. These data and information are not only important for the current design, but also of great values for reuse if similar designs are undertaken in the future. Increasingly, a new product is not created from none but derived from previous models. In this case, effective reuse of design data and information can largely increase efficiency. However, it is not adequate to just record design data to reuse the previous design effectively as they cannot explain the key design issues, e.g. what issues have been considered and why they are addressed in particular ways. Also, the increasing amount of data makes it difficult to identify which kinds of data are truly useful for reuse in the future projects. To solve this problem, design knowledge behind the scene is required, which explains what kinds of data are useful for reuse, how the design has been done, why specific decisions have been made, etc. These kinds of knowledge tend to be tacit and predominantly exist in designers' brains. The current product data management systems mainly focus on the recording and storage of design data, while much more work is required to study the integration of tacit design knowledge and formal design data [1]. Even though a design report can record some tacit knowledge as it gives an account of the design process, it is a timeconsuming task to write a report and it requires considerable effort to find the knowledge recorded due to its unstructured feature. Besides, it is always inefficient to look up a piece of information from a long report, making knowledge retrieval even more difficult. To fill this gap, this research aims to explore an efficient way to capture tacit design knowledge alongside the design process for its effective reuse.

During the engineering design process, a range of design knowledge will be generated including both formal knowledge and informal knowledge. The former is mainly embedded in design, e.g. sketches, diagrams, CAD models, calculations, simulations, standards etc. [2], while the latter, predominantly existing in designer's brains, is often referred as experience. Informal design knowledge is significantly useful as it drives the reasoning process and provides rich context about how various pieces of design data are put into a solution, providing guidance on what kinds of data and information can be reused as well as how to reuse them. In terms of the capture and reuse of knowledge, formal knowledge is easier to capture and manage as it relies on standard and accessible data. On the other hand, informal knowledge is more related to personal experience and thus is more difficult to capture and share in particular when a computer is used to complete this task. In order to capture both of the two kinds of design knowledge for effective use, a knowledge representation model is required to identify how they interact with each other throughout the decision-making process, understand how they can be structured, and develop a representation that allows them to be integrated with the help of computers.

In this study, a Requirement-Function-Behaviour-Structure-Evolution (RFBSE) knowledge representation model is developed to address the issues mentioned above. In order to capture the tacit knowledge in designers' brains, a systematic method should be developed to guide the designers to describe their knowledge in a structural way as a design proceeds and 
represent the descriptions using a format understandable to both humans and computers. The RFBSE model is a high-level knowledge representation model, which is used to identify where useful design knowledge exists and capture this knowledge in a structured way. Specifically, it uses five important elements in engineering design as well as four key design process elements to elicit design knowledge from design activities alongside the whole engineering design process. Also, it integrates the knowledge about design objects with the knowledge about the processes of undertaking these design activities. This integration is underpinned by a structured representation which addresses the interfaces between design objects and design activities, and classifies the pieces of knowledge into engineering knowwhat, know-how and know-why. Apart from giving guidance to designers on knowledge capture, the model can also be used to design and development a software system for design knowledge management which not only records the design data but also captures the underlying design knowledge as the data are produced and recorded.

The rest of this paper is organised as follows. Section 2 reviews relevant work on the representation of design information and knowledge. Section 3 explains the structure and fundamental elements of the RFBSE model, while Section 4 describes practical application and evaluation of the model. The discussion and conclusion of this research are given in Section 5 and 6 respectively.

\section{Related Research}

In the past three decades, several models have been proposed to describe engineering design objects and processes. Some of them are to some extent helpful in facilitating the knowledge management for engineering design. For example the Function-Behaviour-Structure model [3] provides a knowledge representation scheme to describe design object based on its function, behaviour, and structure. Similarly, the Functional Representation model [4] and its variant Causal Functional Representation Language [5] are used to depict design objects through representing functional reasoning. The function, behaviour and structure elements have also been used to describe design objects in different angles. For example, a Function-BehaviourState model [6] has been proposed for functional modelling in conceptual design and a Structure-Behaviour-Function model [7] has been used support analogical design. The common part of these models is to define some basic elements of the design object and use them to explain the nature of the design problem and its solutions systematically.

Based on these fundamental models, further research has been conducted to add more dimensions to them in solving more specific problems. The Situated FBS framework [8] has been proposed in an attempt to extend the FBS model to consider the dynamic characters of the context in which designing takes place. Further to this, a FBS ontology [9] has been developed represent processes despite its original focus was on representing objects. This design ontology provides a uniform framework for classifying processes, and includes higher level semantics in their representation. Additionally, a RFBS model [10] adds requirement analysis as an important element to the FBS model and tries to combine FBS with SysML for 
practical implementation, while a FCBS model [11] uses functional knowledge cells with the FBS model for better comprehending representation of design knowledge in conceptual design. Further developments have also been undertaken on the Functional Representation model. In [12], an ontology for representing design objects is described along with the interactions between these objects, which is used to investigate a range of meanings of the terms 'structure', 'behaviour', and especially 'function' in engineering practice. Based on the SBF concept, an integrated TSBF model [13] has been proposed for the computer-aided conceptual design of mechanisms. The SBF model has also been viewed as a programming language and applied to the development of an interactive model construction tool named SBFAuthor [14].

More recently, some similar models and methods have been proposed. For instance, a Requirement-Function-Behavior-Principle scheme is developed to aid creative design activities in the conceptual design stages [15]. To identify useful knowledge elements, a modelling methodology consisting of three sub-models, i.e. instance model, functional model and dynamic model, has been proposed for knowledge acquisition and modelling [16]. In addition, a knowledge framework for an integrated design environment is developed to capture and manage reflection processes of generating and verifying design concepts, with a core is a three-layered design process model of actions, operations, and argumentation [17]. More studies have been done to investigate practical applications of Function Modelling in industry, with strategies proposed for the facing issues [18]. To improve consistency in the use of the function terminology, a system-relative function terminology is introduced to address the limitations of existing function terminology and some problems with existing function statements [19]. Besides, a Functional Analysis Diagram method is developed to permit the modelling of product functions together with structure, and allow the generation of rich and accurate descriptions of product functionality [20].

Through the review of previous studies and their developments, it can be found that the main focus has always been on the function, behaviour and structure elements of engineering design. Several additional elements have been added to these three basic elements to achieve specific goals. The RFBSE model proposed in this research adopts some methods introduced in previous research, i.e. using the function, behaviour and structure elements as the fundamental part to describe design objects. Compared with the previous models, the RFBSE model considers the engineering design issues from the perspective of knowledge management, and focuses on knowledge capture and representation for a complete design process. As customer-oriented design has become a popular paradigm, the requirement analysis becomes more important. Effective requirement management can decrease product development time and improve product quality [21]. In this case, requirement is added as an important element of the model. Besides, the RFBSE has a fifth element, namely evolution. It refers to the design changes and improvements during the design process, and more importantly explains how useful knowledge is used to interpret design information and generate new information for effective decision-making. This element provides means for combing all the design knowledge related to the design evolution process, linking the other four elements together to provide a context of knowledge generation and utilisation for 
effective knowledge capture and reuse. Apart from these advantages, the RFBSE model also considers how to capture tacit design knowledge, together with its integration with formal knowledge.

\section{The working principles of the RFBSE model}

\subsection{Overview and scope}

The RFBSE model is a high level knowledge representation model which consists of five fundamental elements, i.e. requirement, function, behaviour, structure and evolution, as shown in Figure 1.

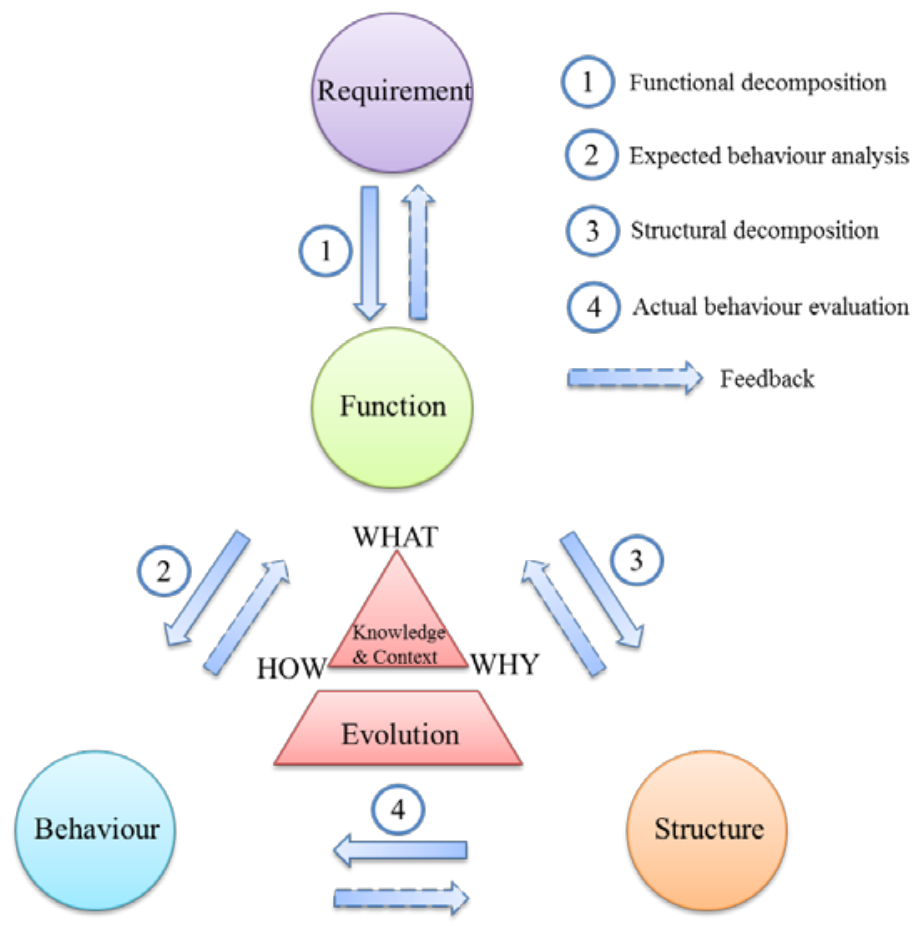

Figure 1. The RFBSE knowledge representation scheme

The purpose of this model is to support knowledge capture and representation during a complete engineering design process. As a knowledge representation model, it firstly provides a systematic method to guide designers in organising and recording the useful knowledge and experience in their minds. Specifically, the RFBSE model focuses on the requirement, function, behaviour, structure and evolution aspects of an artefact, along with the key design tasks related to them, i.e. requirement analysis, functional decomposition, expected behaviour analysis, structural decomposition and actual behaviour evaluation, to build a systematic structure for capturing and representing the knowledge generated, exchanged and utilised during a design process. Such a structure actually provides a context for the knowledge to be captured, not only creating an external environment for knowledge elements but also facilitating their reuse by enabling more efficient navigation. With the systematic structure, formal design knowledge about an artefact, e.g. geometry, materials, manufacture methods, etc., can be firstly captured and organised. For the design knowledge 
on analysis, problem-solving, decision-making, etc., a further method is required to capture and record these kinds of tacit design knowledge in engineers' minds. Detailed knowledge elements in the RFBSE model are classified into engineering know-what, know-how and know-why and are described using concise natural language. These three types of knowledge elements can be used either individually or as a group to describe a complete piece of tacit knowledge. These kinds of tacit knowledge are always linked to relevant formal design knowledge as supplementary explanations. In this way, tacit design knowledge can be integrated with formal design knowledge, with rich design context recorded as part of the integration.

\subsection{Capture an integrated knowledge space}

There are five key areas of the RFBSE model's method for capturing and representing design knowledge, and they work together to create an integrated knowledge space.

\section{a. Requirement analysis}

For an artefact or its component, the requirements to be addressed should always be clarified in the first place. These requirements come from market trends and customer needs, which set the limits and boundaries of the design space. With today's trend in customer-oriented design and customisation, in depth analysis of design requirements has become even more important and a large amount of data needs to be recorded in this first stage of the engineering design process. Previous research has revealed that the development time, product quality and customer value can be improved by effective requirements management [21]. In this case, 'requirement' has been selected as the first important element of the RFBSE model, and the modelling task regarding to this element is to track and capture the knowledge within requirement analysis as well as the relationship between the requirements and the following stages. Specifically, the knowledge be captured is focused on the factors constraining how the subsequent design can be undertaken, such as working conditions, technical parameters, standards to comply with, etc. Moreover, effectively organising the knowledge on requirement analysis will be beneficial for exploring specific functions to meet the raised requirements. In other words, there is a causal relationship between requirement and function which needs to be explicitly described so as to facilitate knowledge reuse.

\section{b. Design object deliberation}

There are three basic elements are often used to describe a design object, i.e. function, behaviour and structure. Specifically, 'function' is used to describe what the artefact is going to perform and is generally obtained to meet certain requirements. In general, an overall function can be further decomposed into several sub-functions. The functional decomposition process involves considerable reasoning and decision-making to identify functional carriers for meeting specific requirements. In this case, designers' knowledge about how to undertake this decomposition process together with the reasons behind key decisions made throughout this process needs to be captured. With the knowledge, the engineers who want to reuse the 
design in the future can understand how to derive the functional structure, what issues are considered as well as why the particular functions have been chosen and elaborated.

The 'behaviour' of an artefact can be regarded as its status of performing functions and in this sense it can be described by several status parameters. According to the function and subfunctions to be performed by the artefact, the desired behaviours of the artefact are analysed through a range of theoretical analysis, calculations, simulations, etc. From this process, the behaviour with optimal status parameters is regarded as the expected behaviour. This expected behaviour determines what should be achieved through design synthesis to obtain the structure of the artefact. When a preliminary design is created, the actual behaviours of the artefact can be determined and evaluated by making comparisons with the expected behaviours based on specific design parameters. During these two processes, i.e. expected behaviour analysis and actual behaviour evaluation, a large amount of useful design knowledge is generated. For example, design knowledge can be captured on how to obtain expected behaviours based on the functions and sub-functions as well as why particular parameters have been changed to achieve improved performance.

The 'structure' element is also an important part of the RFBSE model in capturing design knowledge. The structure of an artefact is derived through design synthesis whereby an abstract description of its functions and expected behaviours is transformed into detailed geometric information. This transformation process involves a lot of connections between the abstract and detailed information and thus is an important source of design knowledge. An artefact can be decomposed into smaller sections to allow more convenient management of its design knowledge, and this structural decomposition can be determined according to its functions and sub-functions. The structural decomposition process not only provides a tree structure to categorise relevant design knowledge but also creates the linkage between function and structure, providing clear and rich design context for the design knowledge captured. In this way, the relationships between the abstract functional requirements and the actual functional carriers can be captured, which are critical for reusing design ideas and solutions.

\section{c. Design evolution}

The fifth element of the model is 'evolution', which refers to the design changes and improvements made during design iteration. The purpose of this element is to capture the designers' knowledge (e.g. what to change, how to deliver the changes and why the possible changes are priorities in a particular way) of improving design object until requirements are met to the largest extent. It focuses on the knowledge about problem-solving and decisionmaking, providing explanations about how useful the knowledge is as well as how to interpret the knowledge in a new context. Design evolution is not simply the design iteration which focuses on modifying a design step by step through evaluating how well predefined targets have been met. Design evolution focuses on the evolving process whereby different versions of a design are delivered, with consideration of more issues related to the fundamental reasons behind the changes and improvements. In other words, design evolution has a broader view and involves more information and knowledge. It includes the design 
iteration within one particular stage of a design, also the change from one version of the design to the next one, as shown in Figure 2.

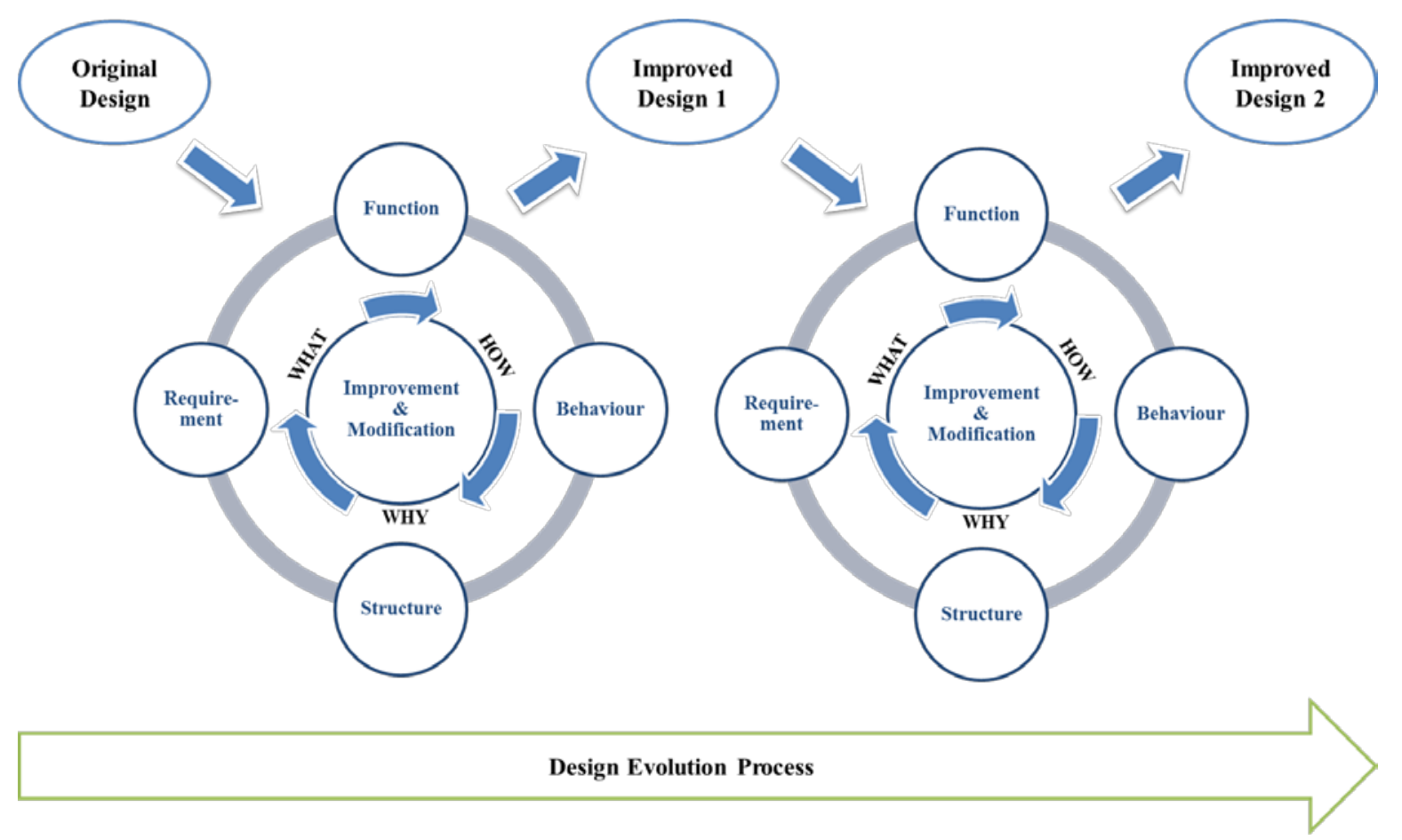

Figure 2. The evolution platform for gathering design information and knowledge

During design evolution, a range of changes and improvements on the design are undertaken, and the factors, causes and efforts behind these changes and improvements are significant and need to be considered carefully. In this case, the useful design knowledge is more likely generated during these processes and covers a wider range of topics. Thus, a platform specific for organising the evolution process is proposed by the RFBSE model to manage this process and more importantly capture and reuse the design knowledge generated within the process. This platform combines the design knowledge related to design evolution and can link the other four elements together to provide a useful context for the knowledge. Specifically, through the design evolution of a product or component, its expected behaviour is firstly identified by analysing individual functional requirements. Then, design improvements are continuously made by changing the structure of a product or component. By checking to what extent the actual behaviours of the improved design meets the expected one, this process will be continuing until an optimal design is achieved. During each step of improvement, useful design knowledge about what changes are made, how they help achieve improvement and why they are developed in certain ways will be captured. The granularity of knowledge representation is determined by the proposed model and takes the forms of engineering know-what, know-how and know-why.

d. Engineering know-what, know-how and know-why

Apart from the five key elements mentioned above, the RFBSE model also considers how to capture tacit design knowledge and integrate it with formal knowledge. Specifically, the RFBSE model firstly creates a systematic structure and uses a diagram-based representation 
for capturing descriptive knowledge contents as well as the relationships between different pieces of knowledge. In this way, tacit knowledge can be integrated with formal design knowledge by linking the nodes within the diagram to external formal knowledge elements such as equations, engineering drawings, CAD models, data tables, etc. In terms of the contents of tacit knowledge, they are recorded using textual description and explanation in the form of a novel integration of engineering know-what, know-how and know-why. Engineering know-what refers to the knowledge for describing and explaining an engineering topic such as a material, technique, physical property, etc.; engineering know-how refers to the knowledge for approaching a problem by elaborating a solution path as well as by identifying, arranging and addressing the issues to be considered; and engineering know-why is the deep knowledge for explaining the reasoning process behind decision which concentres on why a certain phenomenon exits or why a particular action is taken to achieve a particular objective. These detailed knowledge elements aim to achieve fine granularity of information for design knowledge representation, which can be integrated flexibly to describe a complex piece of knowledge. For instance, when capturing design knowledge, know-how is generally created using a number of nodes that linked to know-what nodes for describing objects as well as relationships, and know-why nodes for further explanation, as shown in Figure 3. With the combination of these three types of knowledge elements, a complete piece of design knowledge can be captured and recorded. In this way, tacit knowledge can be structured and integrated with formal knowledge for describing the decision-making and reasoning process through the design tasks.
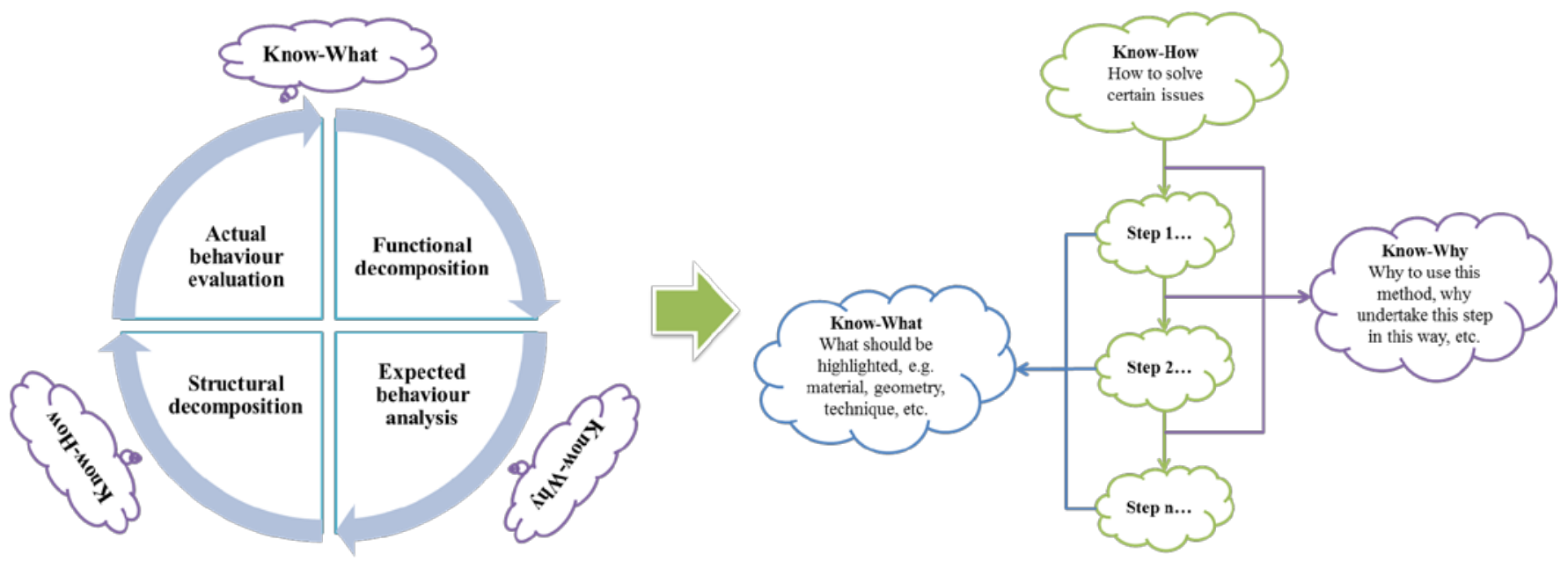

Figure 3. Using know-what, know-how and know-why to describe tacit design knowledge

e. Knowledge and context

Design context has two particular functions: one is for human users and another one is for computer support tools. For the former, design context depicts the background information of the design task, i.e. context of working, identifying which task to undertake, what kind of problem to solve, what parameters to consider, etc. This can facilitate designers' work in both knowledge capture and reuse as knowledge can be better understood. For the later, a clear design context is required in order to retrieve design knowledge to support designers' tasks, 
as design context can help locate relevant information. For instance, the intelligent recommendations provided by computer tools during the collaborative design process are highly dependent on design context. Thus, design context is an import factor that determines effective design reuse as it helps locate the useful information and on this basis facilitate the knowledge understanding and reuse.

The RFBSE model tries to capture design context alongside useful information and knowledge captured by addressing two aspects, as shown in Figure 4.

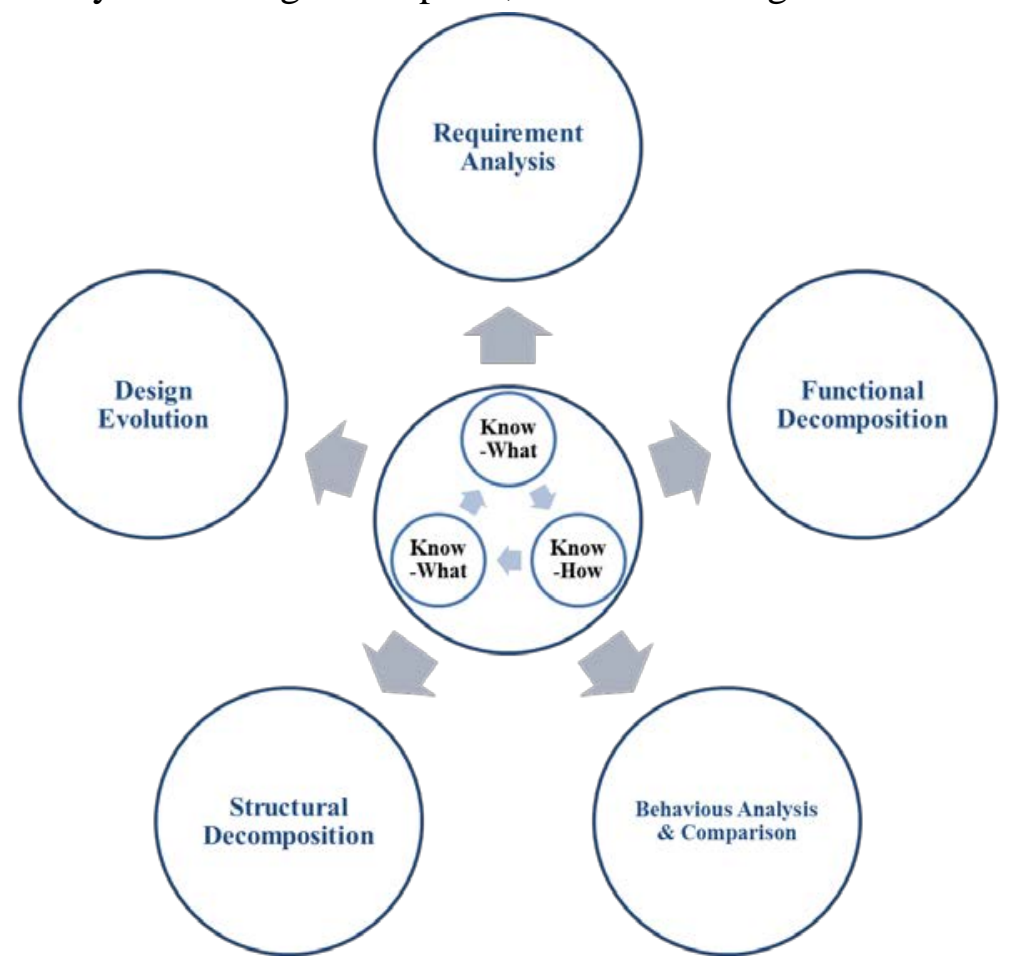

Figure 4. Capturing design context for relevant information and knowledge

Specifically, one is the systematic tree structure built by the model and another one is to use the tacit knowledge captured in the form of know-what, know-how and know-why. The tree structure can be created in various areas, including requirement analysis, functional decomposition, behaviour comparison and analysis, structural decomposition, and design evolution. These specified tree structures combine the required background information in order to capture the design knowledge behind the scene, which is actually providing a context for the design knowledge. Moreover, the relationship created by the tree structure helps to locate the knowledge captured. In this case, effective retrieval and intelligent recommendation on specific design information and knowledge can be achieved through exploiting specified contexts. On the other hand, the knowledge captured in the form of know-what, know-how, know-why provides three symbols on what kinds of knowledge they are, which is beneficial to identify their usage. In other words, the knowledge element itself provides useful design context by integrating different pieces of information and making the relationships between them more explicit. 


\section{Application and evaluation}

\subsection{Capturing useful knowledge through design process}

The RFBSE model is proposed to help engineering designers capture their knowledge and experience alongside design process. Thus, the key issues for the model's application are on how to give the designers a clear clue in structuring and recording their design knowledge and experience in their minds. The representation scheme of the RFBSE model has been shown in Figure 1, which clearly shows the key elements and design tasks that are used for the knowledge capture and representation. The model actually provides a way of guiding engineers where design knowledge likely exists and how to capture it for reuse. Within a design process, designers firstly need to think about what kinds of requirements the design is going to meet. Then the concentration moves to the design object itself by considering function, behaviour and structure. Next, the focus comes to how to improve the design. This procedure has been concluded into four main design tasks by the model, i.e. functional decomposition, expected behaviour analysis, structural decomposition and actual behaviour evaluation. In this case, design knowledge generated during the design process can be organised based on the issues addressed through undertaking the four specific tasks. In other words, these four elements are created to systematically structure design knowledge, which are described in detail in the following paragraphs.

Functional analysis is a formalised way of describing customers' requirements and transforming them into detailed functions. In this case, the functional decomposition task includes transforming these requirements into an artefact's functions and then dividing the main functions into several sub functions. Thus, the knowledge generated in this task can be organised by linking what kinds of function can be used to meet certain requirements and why the functional decomposition has been undertaken in the specific way, as shown in Figure 5.

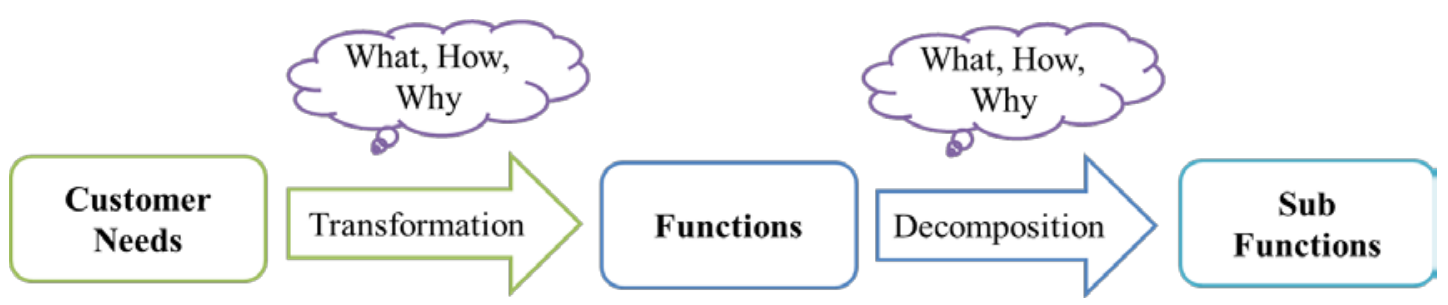

Figure 5. Knowledge exists on requirement analysis and functional decomposition

Customer needs are the most important input at the beginning of a design project, which indicate the goals and expectations of a product or service. Requirement analysis focuses on meeting the customer needs, which contains a range of valuable knowledge on how to meet the requirements. Besides, Product Design Specification (PDS) is created based on the analysis of these user requirements. How to transform the requirements into a formal PDS and subsequently to the functions that need to be achieved to fulfil the requirements should also be clarified. As customisation becomes increasingly popular, design requirements can be diverse and sometimes conflict with each other, which mean that a large amount of tacit knowledge is involved within collective efforts of people with different roles such as design 
engineers, managers and marketing personnel. In this case, the knowledge about correlations between certain functions and the requirements they aim to address need to be identified and captured to provide guidance for the later design stages. In the RFBSE model, the requirement element is linked with specific function element to clarify this relationship and the identification of these relationships greatly relies upon designers' knowledge and experience.

Through requirement analysis, several functions are identified to meet the requirements, which can be subsequently decomposed into more detailed sub-functions. Then, the task of expected behaviour analysis is undertaken to find out the key indicators for evaluating how the function and sub-functions can be implemented. This process includes several activities, such as idea generation and evaluation as well as a range of decision-makings. The knowledge generated at this stage mainly comes from the rationale behind design divergence and convergence, problem-solving, and decision-making. The knowledge generated within these processes are classified into Know-what, Know-how, and Know-why knowledge elements to describe the valuable design knowledge generated, as shown in Figure 6.

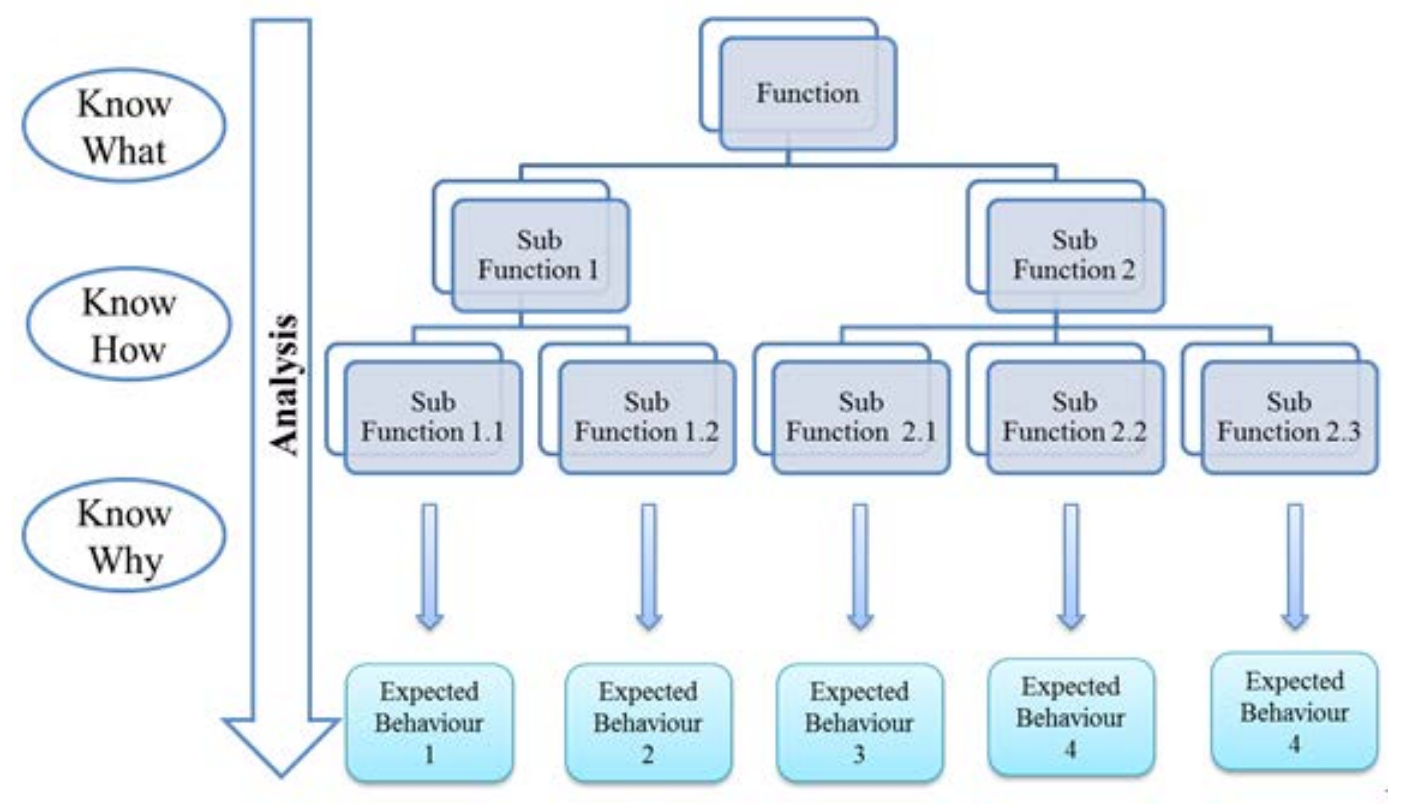

Figure 6. Functional decomposition and expected behaviour analysis

The expected behaviour analysis task is used to transform functions and sub-functions into the expected behaviours. Alongside the analysis, design synthesis is undertaken to obtain necessary structure and form to realise the specific expected behaviour, as shown in Figure 7. In order to organise the design knowledge effectively and capture the specific context with it, a decomposition of the generated structure should also be undertaken. The structural decomposition provides a way to organises the information and knowledge related to each component and sub-component of an artefact systematically. 


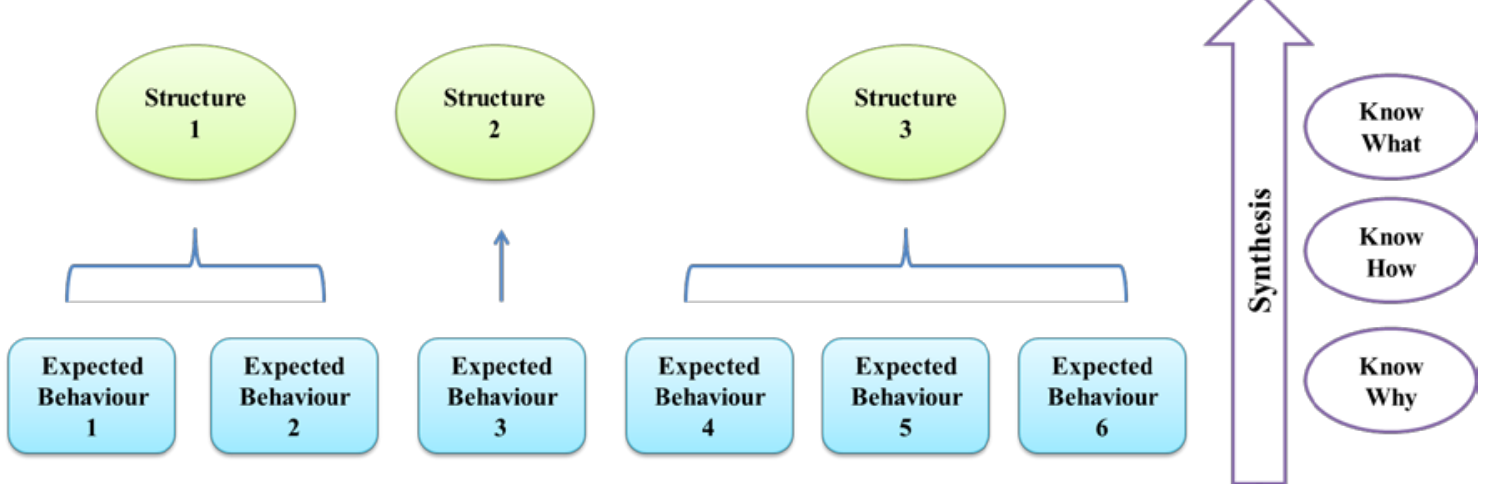

Figure 7. Design synthesis from expected behaviour to structure

When the structure of an artefact or a component is obtained through design synthesis, its actual behaviour can be determined. Then, this actual behaviour should be compared to the artefact's expected behaviour for evaluation and improvement. During this process, a range of modifications and improvements are made through considering particular issues, which is regarded as a design evolution process. Within this design evolution, a range of design knowledge will be generated especially the tacit knowledge. This tacit knowledge is related to decision-making, problem solving and design argumentation, which requires a specific method to link different pieces of information together. The method provided by the RFBSE model is to track each status of the artefact, based on an analysis of its actual behaviour after changes, as shown in Figure 8.

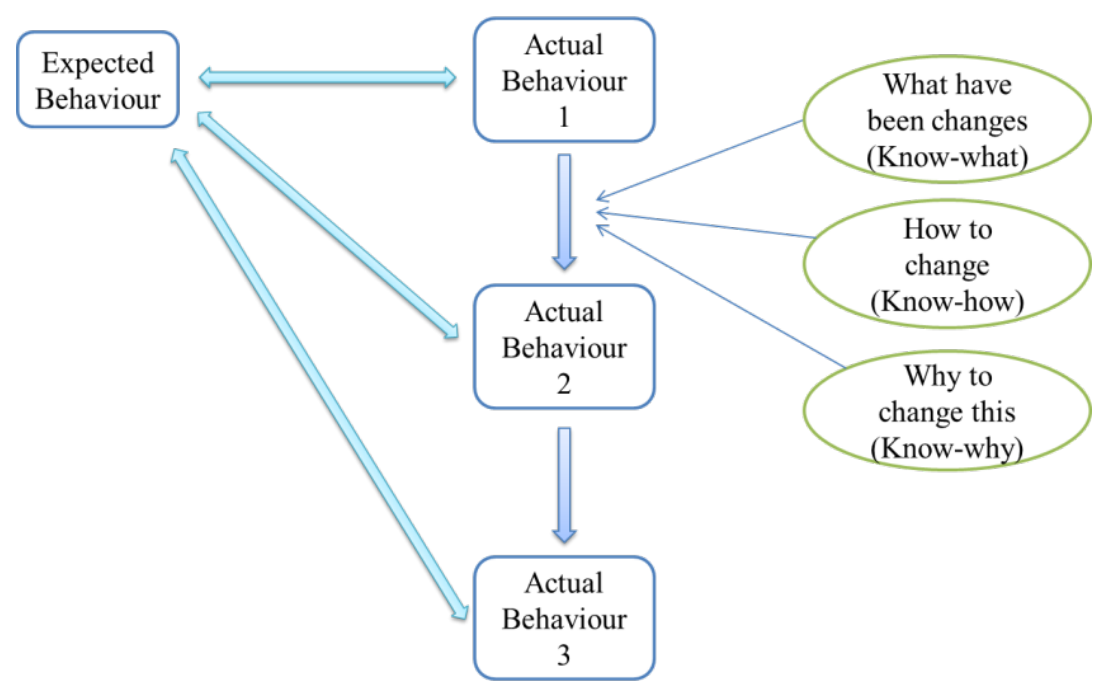

Figure 8. Capturing design knowledge through evaluating actual behaviour with expected behaviour

From a status improved to the next one, e.g. actual behaviour 1 to actual behaviour 2, the design knowledge generated in this process can be organised into what have been changed (know-what), how to change it (know-how) and why to change this (know-why). Also, based on this procedure, the modifications and improvements on an artefact or a component can be tracked. As this procedure provides a context for relevant design data and information generated and used, it can improve the efficiency of locating the useful design information and knowledge when reusing the previous designs. 


\subsection{A case study}

This section aims to give more details based on an engineering design project, i.e. an intake system design of a vehicle. Intake system is an important part of a vehicle' powertrain, which controls the amount of air flown into the engine and subsequently adjusts the fuel supply based on the air flow rate. The RFBSE model is used as a guidance to capture designers' useful knowledge and experience through the design process of this system. At the beginning of the process, customer requirements are gathered and analysed, and then the functions which can be used to meet these requirements are explored. These functions are the objectives to be achieved and can be further decomposed into several sub-functions in order to clarify and simplify the tasks, as shown in Figure 9.

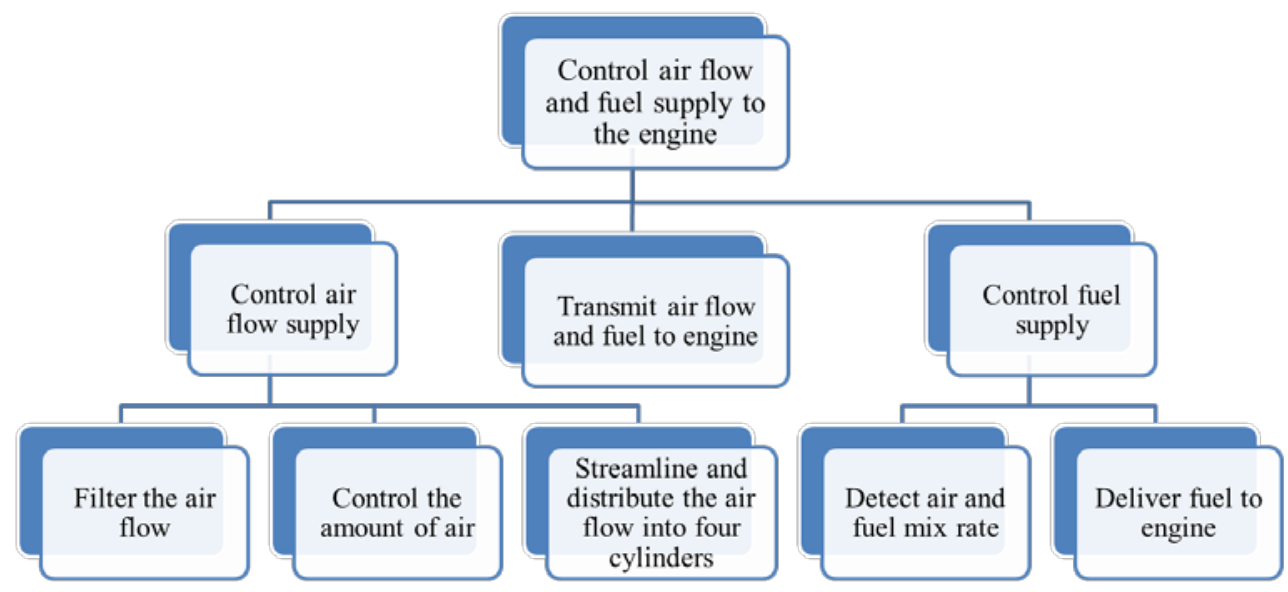

Figure 9. Functional decomposition of the intake system

During this process, design knowledge predominantly exists in two aspects-one is what functions are needed to meet certain requirements and another is on what sort of subfunctions are needed to realise the overall function, how they will work together and why a particular sub-function is used. These kinds of knowledge can generally be captured in the form of know-what, know-how, and know-why, as shown in Figure 10. The above functions and sub-functions will be transformed to expected behaviours which are the ideal results for achieving the certain functions. During these transformations, a range of idea generation and evaluation are undertaken by the designers, which is the expected behaviour analysis task mentioned in the RFBSE model. Through this task, solutions need to be generated and important decisions need to be made, particularly in the transformation from functional descriptions into performance requirements and then into the specific status and parameters, as shown in Figure 11. 


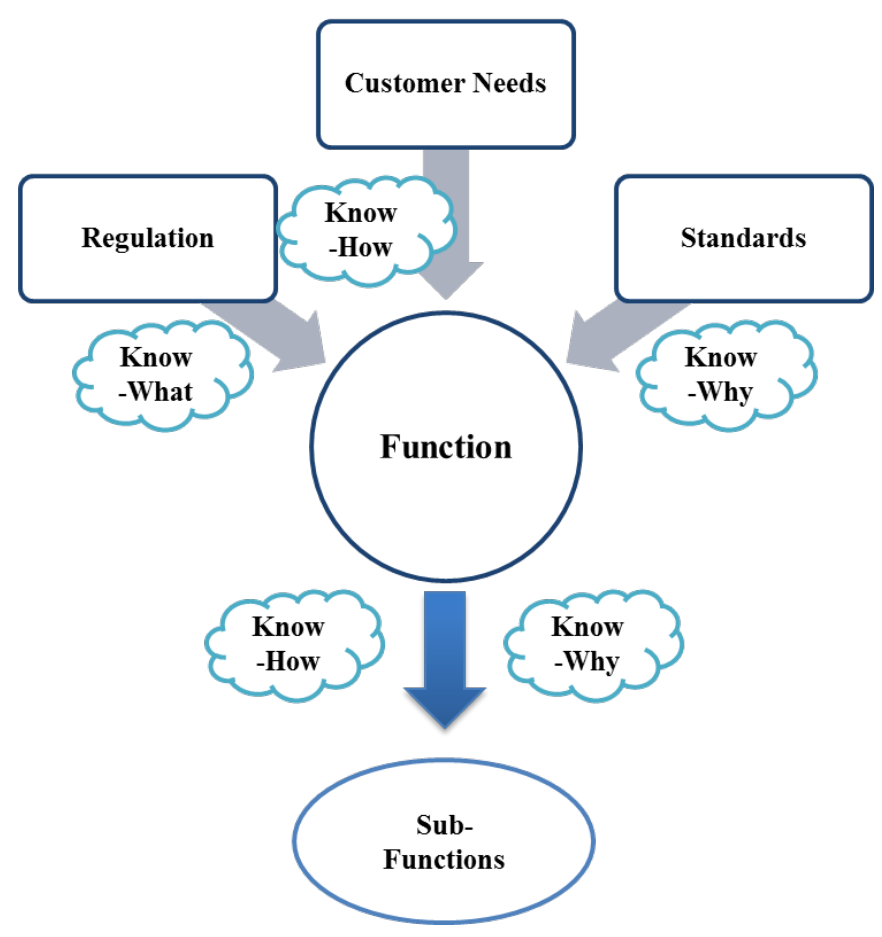

Figure 10. Capturing design knowledge through requirement analysis and functional decomposition

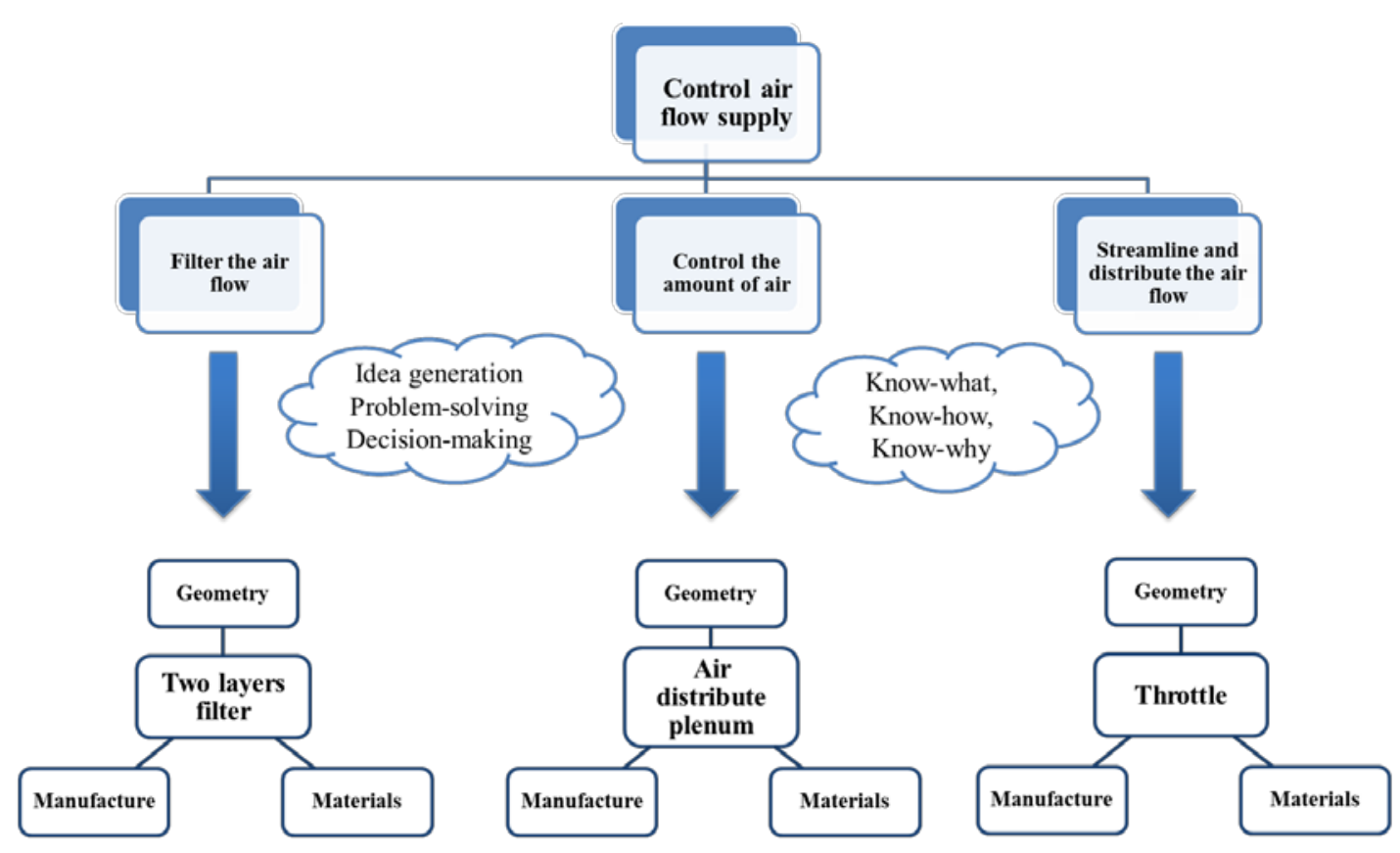

Figure 11. Capturing design knowledge through expected behaviour analysis

The underlying knowledge holds the key in deciding what are the right issues to be considered, how to solve these issues and why to take the particular actions and decisions. Thus, it should be captured in the form of know-what, know-how and know-why. 
In order to give forms to the components of an artefact effectively, structural decomposition is undertaken to establish an optimal layout for the artefact and identify the special and physical relationships between different components. In this intake design example, the intake system has been decomposed into five components, namely air filter, throttle, intake plenum, connector, and fuel injector, as shown in Figure 12. Generally, a structural decomposition results in a number of components, each of which performs a particular function. Take the air intake system as an example, each component in Figure 11 realises a specific function that the system needs to perform. Specifically, the air filter is used to filter the air flowing into the engine; the throttle controls the amount of air; the intake plenum streamlines the air flow and distributes it into four parts which connect to the four cylinders of the engine; the connecter determines the location of the intake system and connect it to the engine; and the fuel injector controls the amount of fuel supply to the engine.

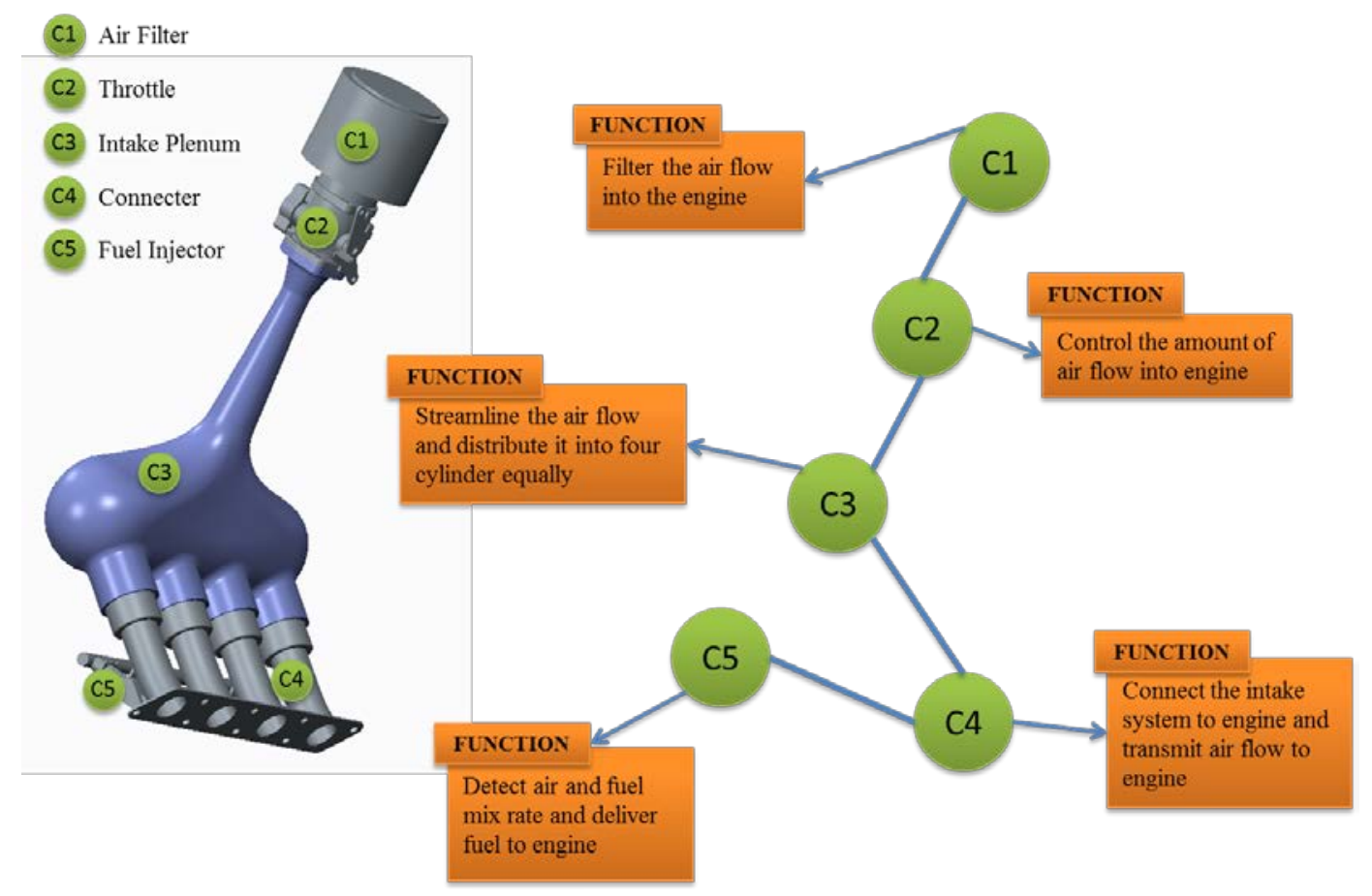

Figure 12. Structural decomposition of the intake system

For each component, it can be further divided into several sub-components if functions performed by these sub-components need to be analysed separately to facilitate problem solving and understanding. With this structural decomposition, useful design information and knowledge related to the intake system can be organised in a systematic way. Such a structural decomposition not only provides a straightforward way of understanding the relationships between different components but also combines the geometric information of component with rich design contexts for better reusing the underlying design knowledge, as shown in Figure 13. 


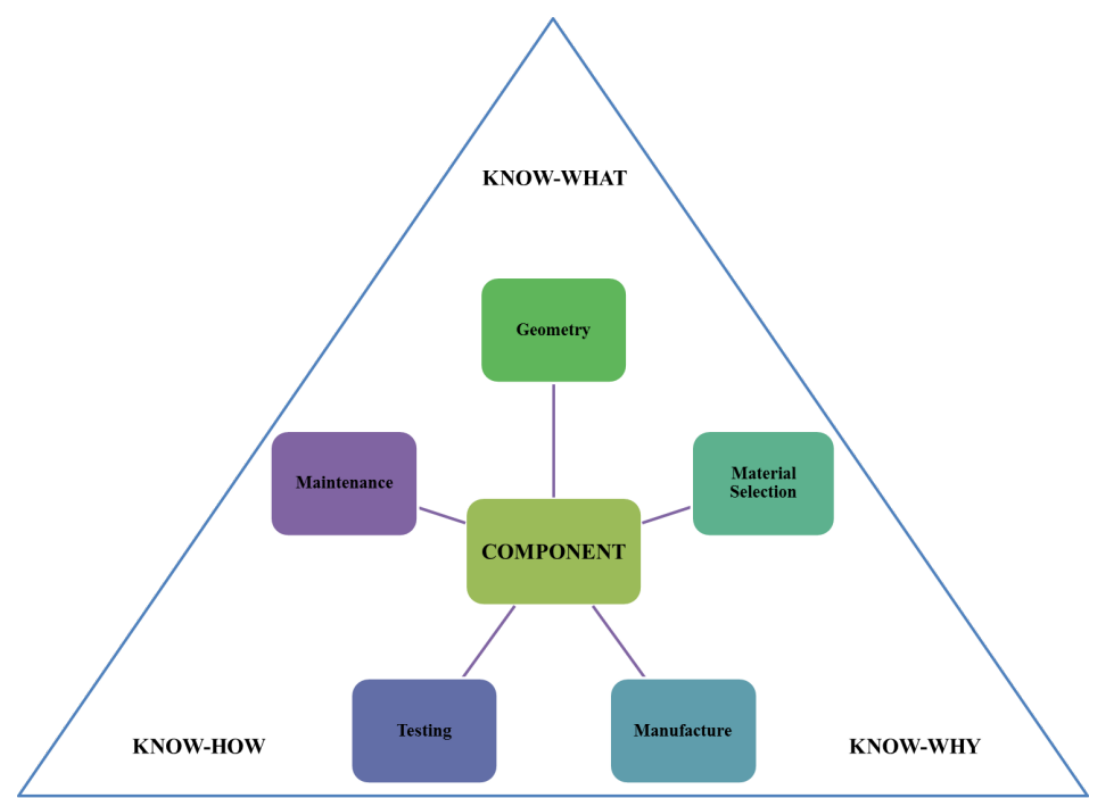

Figure 13. Capturing design knowledge within a specific context

Moreover, useful design knowledge will also be generated through the changes and improvements made on the existing designs. With the embodiments of these components, their actual behaviours are determined and can be evaluated by comparing with their expected behaviours identified previously. Figure 14 gives an example of the intake plenum to explain the actual behaviour evaluation process through which necessary changes and improvements are continuously made in order to make the actual behaviour close to the expected behaviour as much as possible. This process involves a large amount of knowledge related to what issues to consider, how to improve performances and why to make a particular change, etc. Therefore, the evolution component of the RFBSE model can be used in this task to capture the decision-making process in achieving an optimal solution.

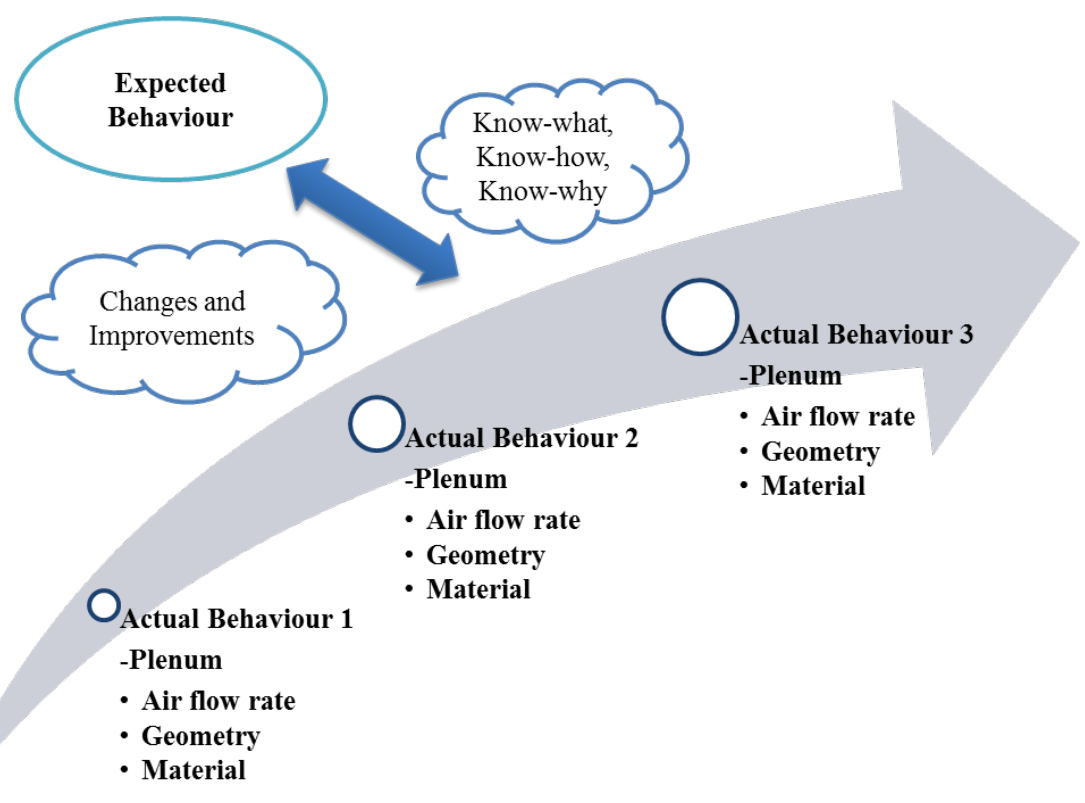

Figure 14. Capture design knowledge through actual behaviour evaluation 
Overall, with the guidance of the RFBSE model, useful design knowledge generated during the design process can be identified and captured. Also, the model supports the problem solving process by providing a number of specific design tasks through which useful knowledge is generated together with a complete and clear design context for its effective reuse. For the practical implementation of the RFBSE mode, a Web-based knowledge management system has been developed, with its main knowledge capture Graphic User Interface (GUI) shown in Figure 15. The idea of capturing design knowledge through the design process is to discover and record knowledge as design issues are resolving rather than writing a design report at the end of a project. The knowledge capture tasks focus on the four main design tasks described in the RFBSE model, i.e. functional decomposition, expected behaviour analysis, structural decomposition and actual behaviour evaluation. The intake system design example mentioned above is implemented in the system, with examples shown in Figure 16 and 17.

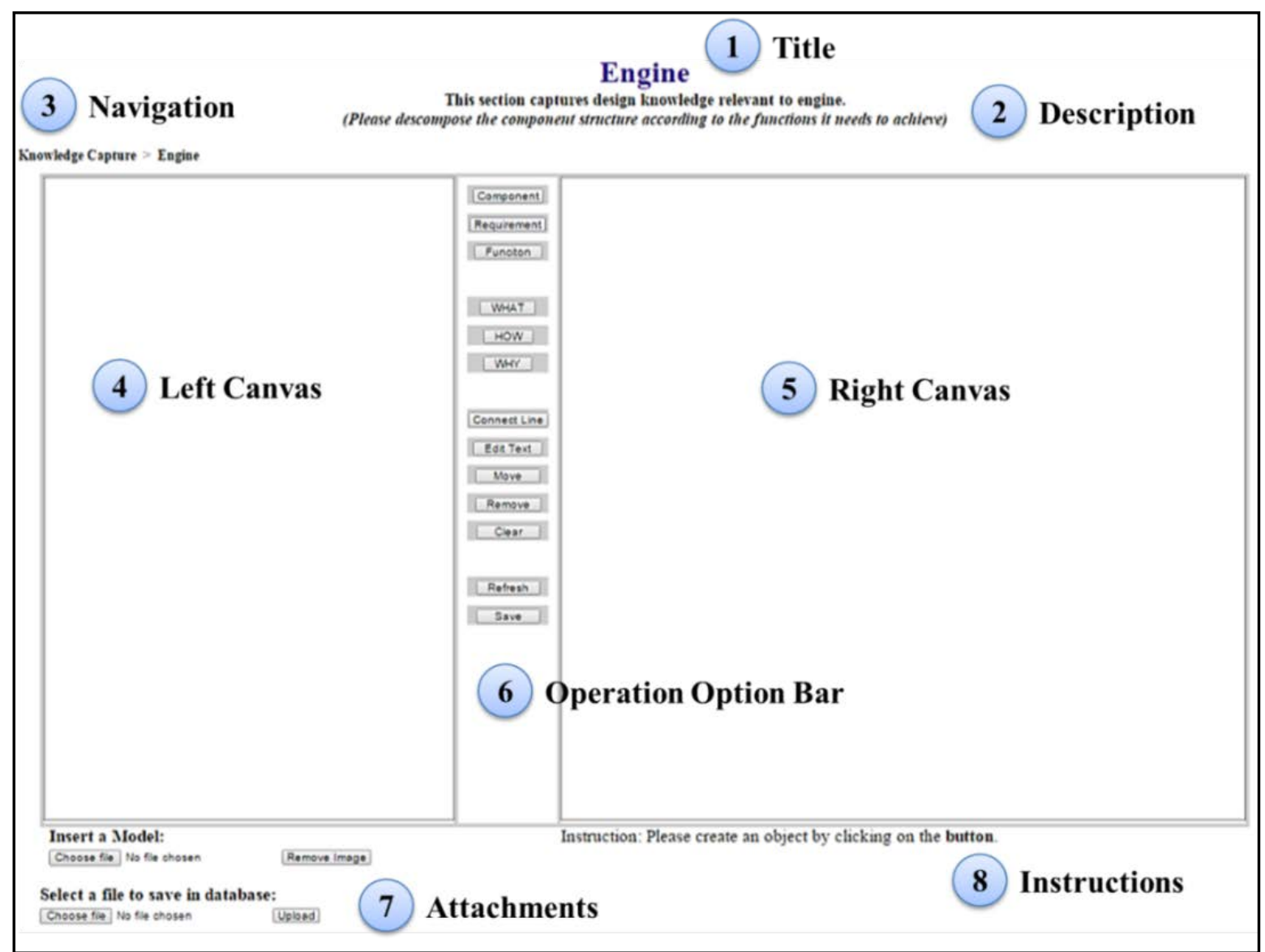

Figure 15. Knowledge capture GUI of the Web-based knowledge management system 


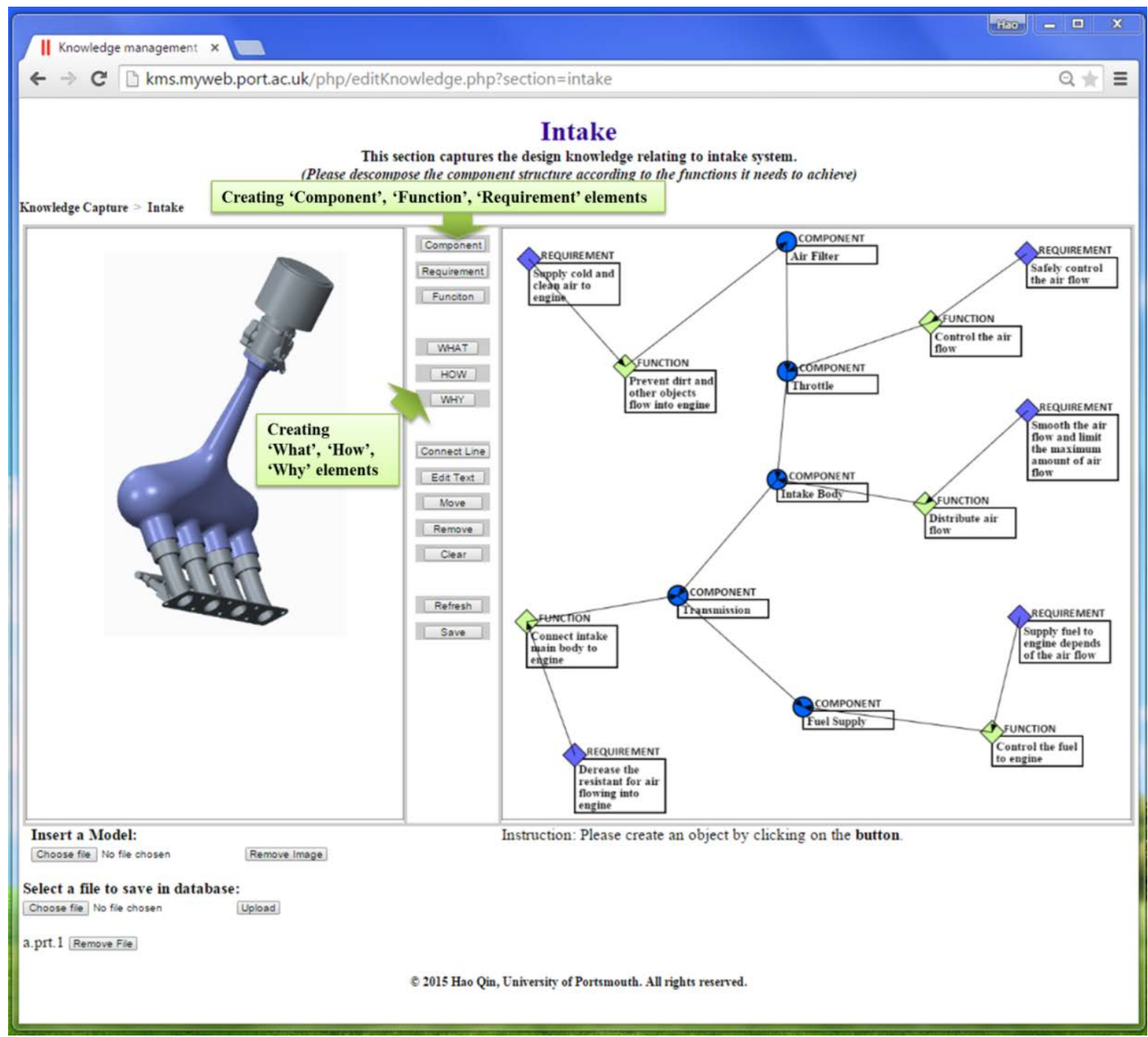

Figure 16. Structural decomposition in the system

Figure 16 shows how the system is used to capture and represent design knowledge related to the intake system design. Specifically, on the Left Canvas, a CAD model is displayed to give engineers a straightforward way of understanding the design object, while useful design knowledge is organised and recorded on the Right Canvas. For each component in the design object, the detailed function and relevant requirements are clearly identified. Additionally, each element created in the knowledge capture GUI can be double-clicked to open a new GUI for capturing more details related to the element. Any supplementary documents can be uploaded to the system through the GUI as attachments, e.g. calculations and simulation results, in order to achieve the completeness of the design knowledge captured. As the system has a particular focus on capturing the knowledge about design evolution, a GUI specific for capturing design evolution is developed in the system. The example in Figure 17 shows how the system can be used to capture the knowledge generated and exchanged during design evolution of the intake body. Within this GUI, the knowledge generated during a design evolution process can be captured and organised with the guidance of the RFBSE model. 


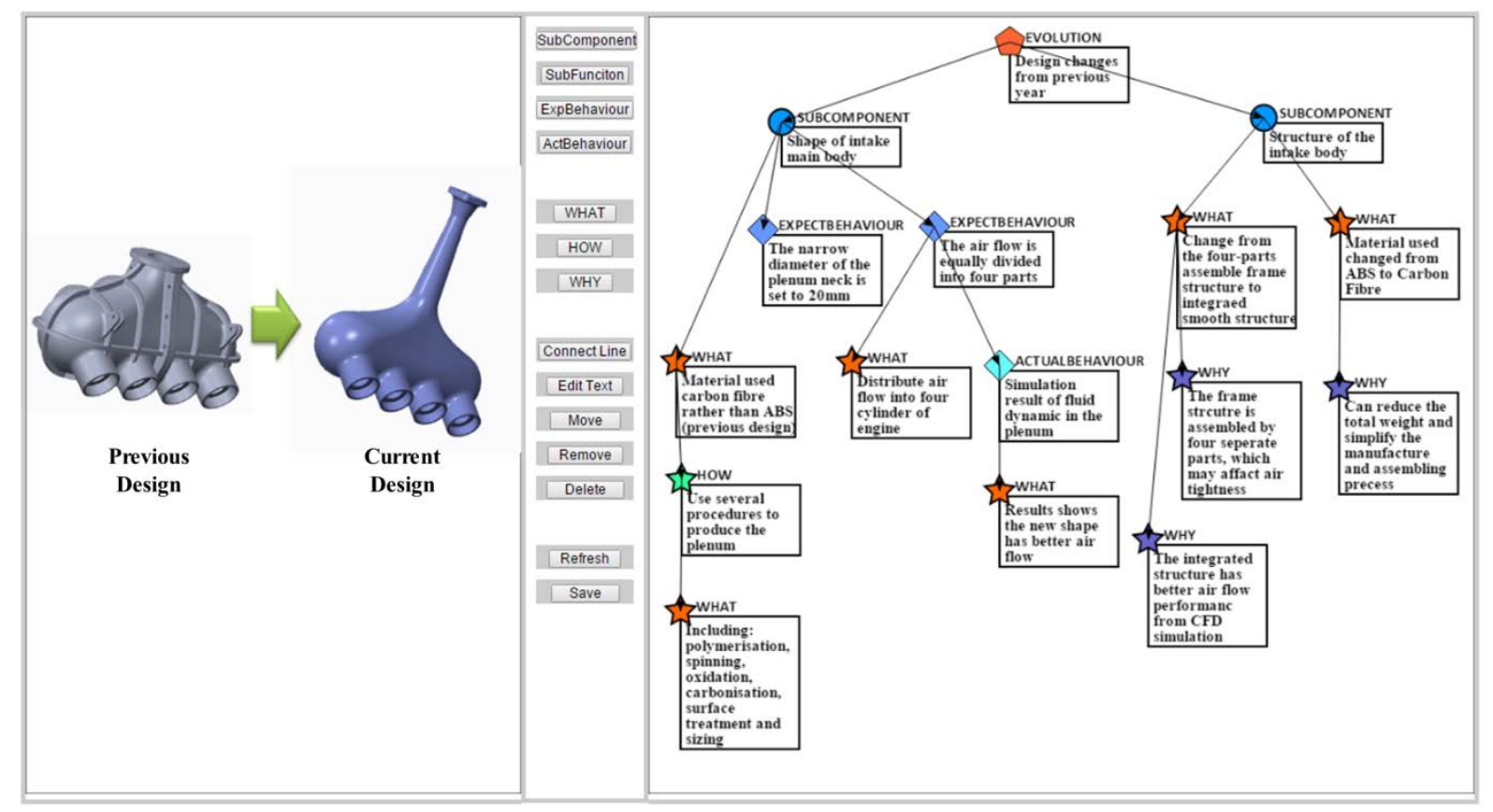

Figure 17. Capturing the design evolution process of a component

Through this systematic method of organising design knowledge, designers can capture and record useful knowledge as a design issues is being addressed. In addition to the designers working on the issue, other people across the development chain of a company, e.g. sales person, manufacture engineers and services engineers, can also contribute to the creation of knowledge elements as well as benefit from the elements in other stages of the chain. For example, the improvements achieved during the design evolution in Figure 17 are made in response to suggestions from manufacture engineers. Sales people can also give inputs to the design based on customer requirements, and adjust their marketing plans according to the improvements of the design. In addition, the specific knowledge elements captured can help service engineers to make informed decisions when doing maintenance by referring to reasons of changes and the change propagation amongst key design parameters. In this sense, the proposed system not only provides useful supports to design engineers but also benefits the development chain of a company.

\subsection{Evaluation of the model}

Apart from demonstrating the application of the RFBSE model in a practical engineering design project, the model has also been compared with previous models for evaluation. From early research in the area of describing design objects and design processes for engineering design, several models have been proposed including the Function-Behaviour-Structure (FBS) model [3], the Functional Representation(FR) model [4], the Structure-Behaviour-Function (SBF) model [7], the prescriptive model of engineering design process [22], and Design Rationale [23]. Compared to these models, the RFBSE model has a distinct feature of enabling an integrated knowledge representation, which employs the concepts of function, 
behaviour and structure in Gero's FBS model [3] for describing design objects whilst incorporating another two important elements, namely requirement and evolution. Function, Behaviour and Structure are the three classic elements widely accepted by researchers for describing design objects. Since the RFBSE model is proposed to capture and represent design knowledge, it not only uses these elements to describe knowledge about design objects but also focuses on the links between these elements and the problem solving and reasoning processes in the tasks of functional analysis, structural decomposition, and behaviour analysis and evaluation. In addition, the requirement element is employed in the model as it determines the goals of the design project. Moreover, the transformation of a requirement into specific functions involves highly useful knowledge related to understanding customer needs and establishing an effective functional structure particularly in the context of customer-centred design and customisation. The last element of the RFBSE model is design evolution which considers the dynamics characteristic of design knowledge and focuses on capturing the design knowledge generated on design changes and improvements as well as designers’ evolving knowledge needs.

A number of factors have been proposed to be used as the criteria for evaluating the knowledge models, which involve three main areas: model description, application in knowledge representation and implementation by computer support tools. On this basis, comparisons have been made between the RFBSE model and several existing models. The models chosen for comparison include: (1) FBS [3] and its variants such as RFBS [10] and FCBS [11]; (2) FR [4] and its extension CFRL [5]; (3) SBF [7]; (4) Design Rationale model [23]; and (5) Pahl' design process model [22]. The details of the comparison are summarised in Table 1. 
Table 1. Comparison of the RFBSE model with several similar previous models

\begin{tabular}{|c|c|c|c|c|c|c|c|c|c|}
\hline & & FBS & RFBS & FCBS & FR/CFRL & SBF & $\begin{array}{c}\text { Design } \\
\text { Rationale }\end{array}$ & $\begin{array}{l}\text { Pahl's Design } \\
\text { Process Model } \\
\end{array}$ & RFBSE \\
\hline \multirow{4}{*}{ 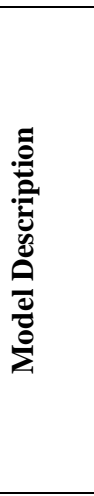 } & Subject of Description & $\begin{array}{l}\text { Design objects } \\
\text { and their } \\
\text { relationships }\end{array}$ & $\begin{array}{l}\text { Extend FBS } \\
\text { and implement } \\
\text { in SysML }\end{array}$ & $\begin{array}{c}\text { Extend FBS } \\
\text { with functional } \\
\text { cell }\end{array}$ & $\begin{array}{c}\text { Functional } \\
\text { modelling }\end{array}$ & $\begin{array}{c}\text { Analogical } \\
\text { reasoning }\end{array}$ & Design rationale & $\begin{array}{l}\text { Design } \\
\text { process }\end{array}$ & $\begin{array}{l}\text { Knowledge } \\
\text { representation } \\
\text { and reuse }\end{array}$ \\
\hline & $\begin{array}{l}\text { Systematic Description } \\
\text { of design objects or } \\
\text { design process }\end{array}$ & $\begin{array}{l}\text { Function, } \\
\text { Behaviour, } \\
\text { Structure }\end{array}$ & $\begin{array}{l}\text { Requirement, } \\
\text { Function, } \\
\text { Behaviour, } \\
\text { Structure }\end{array}$ & $\begin{array}{c} \\
\text { Function, } \\
\text { Functional cell, } \\
\text { Behaviour, } \\
\text { Structure }\end{array}$ & $\begin{array}{c}\text { Functional } \\
\text { decomposition }\end{array}$ & $\begin{array}{l}\text { Structure, } \\
\text { Behaviour, } \\
\text { Function }\end{array}$ & $\begin{array}{l}\text { Problem solving } \\
\text { process }\end{array}$ & $\begin{array}{l}\text { Engineering } \\
\text { design process }\end{array}$ & $\begin{array}{c}\text { Requirement, } \\
\text { Function, } \\
\text { Behaviour, } \\
\text { Structure, } \\
\text { Evolution }\end{array}$ \\
\hline & $\begin{array}{l}\text { Capture design } \\
\text { changes and evolution }\end{array}$ & No & No & No & No & No & Yes & No & Yes \\
\hline & $\begin{array}{l}\begin{array}{l}\text { Capture design } \\
\text { knowledge context }\end{array} \\
\end{array}$ & No & No & Yes & No & No & Yes & No & Yes \\
\hline \multirow{4}{*}{ 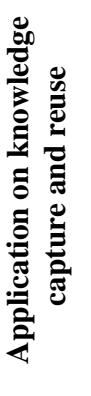 } & $\begin{array}{l}\text { Knowledge } \\
\text { representation }\end{array}$ & $\begin{array}{c}\text { Abstract } \\
\text { schema }\end{array}$ & $\begin{array}{l}\text { SysML } \\
\text { diagram } \\
\end{array}$ & Functional cells & $\begin{array}{c}\text { Functional } \\
\text { decomposition }\end{array}$ & $\begin{array}{c}\text { Analogy } \\
\text { reasoning }\end{array}$ & $\begin{array}{c}\text { Graphic } \\
\text { representation } \\
\end{array}$ & $\begin{array}{c}\text { Procedure } \\
\text { representation } \\
\end{array}$ & $\begin{array}{c}\text { Graphic } \\
\text { representation } \\
\end{array}$ \\
\hline & $\begin{array}{l}\text { Integration of multi- } \\
\text { faceted knowledge }\end{array}$ & N/A & N/A & N/A & N/A & N/A & N/A & N/A & Yes \\
\hline & Confidence of reuse & Medium & Medium & High & Medium & High & High & Medium & High \\
\hline & $\begin{array}{l}\text { Support for design } \\
\text { knowledge reuse }\end{array}$ & $\begin{array}{c}\text { Conceptual } \\
\text { design process }\end{array}$ & $\begin{array}{c}\text { Conceptual } \\
\text { design process }\end{array}$ & $\begin{array}{l}\text { Conceptual } \\
\text { design process }\end{array}$ & $\begin{array}{c}\text { Conceptual } \\
\text { design process }\end{array}$ & $\begin{array}{c}\text { Analogical } \\
\text { design and } \\
\text { case-based } \\
\text { reasoning }\end{array}$ & $\begin{array}{l}\text { Capture design } \\
\text { rationale } \\
\text { through design } \\
\text { process } \\
\end{array}$ & $\begin{array}{c}\text { Describing } \\
\text { design process }\end{array}$ & $\begin{array}{c}\text { Capture design } \\
\text { knowledge } \\
\text { during design } \\
\text { process } \\
\end{array}$ \\
\hline \multirow{4}{*}{ 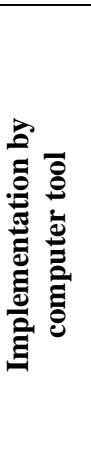 } & $\begin{array}{l}\text { Applicable } \\
\text { computer-aided tool }\end{array}$ & N/A & $\begin{array}{l}\text { Using SysML } \\
\text { for modelling }\end{array}$ & $\begin{array}{l}\text { Computer-aided } \\
\text { conceptual } \\
\text { design tool }\end{array}$ & N/A & IDEAL & DRed & N/A & $\begin{array}{c}\text { Web-based } \\
\text { knowledge } \\
\text { management } \\
\text { system } \\
\end{array}$ \\
\hline & $\begin{array}{l}\text { Representation in } \\
\text { software }\end{array}$ & N/A & $\begin{array}{l}\text { SysML } \\
\text { diagram }\end{array}$ & $\begin{array}{l}\text { Functional } \\
\text { sketches }\end{array}$ & N/A & $\begin{array}{l}\text { Case-based } \\
\text { reasoning }\end{array}$ & $\begin{array}{l}\text { Design rationale } \\
\text { diagram }\end{array}$ & N/A & $\begin{array}{c}\text { Graphic } \\
\text { knowledge } \\
\text { representation } \\
\text { diagram } \\
\end{array}$ \\
\hline & $\begin{array}{l}\text { Support for } \\
\text { collaborative working } \\
\text { environment }\end{array}$ & N/A & No & No & N/A & No & Yes & N/A & Yes \\
\hline & Extendibility & N/A & Medium & Medium & N/A & Low & High & N/A & High \\
\hline
\end{tabular}




\section{a. Model description}

In terms of the model description aspect, the object and focus of each model is analysed and compared to find out the differences. Most of these models are either focused on describing design objects or used to describe the design process. A number of conclusions can be drawn from the analysis and comparison: (1) the FBS model focuses on clarifying the relationships between the design elements; (2) the RFBS model is based on FBS and tries to combine it with SysML; (3) the FCBS model tries to combine the functional cells concept with FBS; (4) the FR and the subsequent CFRL model aim to describe the functions in a device through functional modelling; the purpose of SBF model is to support analogical design; (6) the Pahl's prescriptive model of the engineering design process aims to establish the key stages and steps so as to provide guidance on the tasks that need to be carried out; and (7) the Design Rationale emphasises capturing the decision-making with a particular focus on issues, alternatives and arguments. Compared with these models, the RFBSE model emphasises an integrated representation aiming to address both the codification and personalisation aspects of design knowledge. It not only identifies the design objects and their relationships but also considers the know-how and knows-why generated, used and shared throughout the reasoning and problem-solving processes. Mover, the RFBSE model takes a dynamic view on design knowledge, emphasising the evolution of design knowledge throughout a design project or across different projects so as to better address the diversity of designers' knowledge needs.

For the other aspects, few of the previous models consider capturing design context together with design knowledge although it is significant in improving the reuse efficiency. The RFBSE model provides a method to build a systematic framework for organising design knowledge, which can also record the context of generating and using knowledge. Furthermore, the previous models do not provide a method for capturing design knowledge through the design evolution process. Nowadays, new designs are predominantly developed based on existing solutions, by making necessary improvements to meet new customer needs. The RFBSE model has a particular focus on design evolution which involves the analysis of new needs and new technologies comparing to the existing design. As such, it can capture the useful knowledge about the particular issues considered, the linkage between existing solution and new requirements and the construction of new solutions. In this way, it can better fulfil designers' knowledge needs particularly in the context of a user-centred knowledge management solution.

\section{b. Application in knowledge representation and reuse}

As shown in Table 1, each model has its specific way of representing knowledge. The RFBSE model emphasises using graphical diagram-based representation, as it is a visual way of representation which is suitable for organising tacit knowledge. In terms of the ways of organising design knowledge, the previous models do not consider how to integrate knowledge from multiple sources. In the RFBSE model, multi-faceted knowledge has been classified into know-what, know-how, and know-why, and they are integrated to describe a complete piece of knowledge with a rich context. In this way, the knowledge captured is 
better represented in terms of both the amount of information and the granularity of information, which increases the confidence of reuse. Although existing models can assist design reuse in some ways, few of them can support capturing the knowledge about design objects and put it in a context formed by the process issues. In other words, they only focus a particular aspect and design knowledge is not generated as an integral part of the design process. On the contrary, the RFBSE model aims to capture design knowledge in a number of key design tasks so as to allow its effective reuse in the later stages of the project or in future projects.

\section{c. Implementation by computer tools}

Some of the models listed in Table 1 have relevant computer support tools developed for their practical implementation. Most of the tools use diagram-based representation, which shows that it is a good way for the representing the knowledge. The diagram-based representation can give a clear view on what the information is representing as well as identifying the relationships between different pieces of information. In modern product development, knowledge capture and reuse is increasingly conducted within a geographically distributed environment, which entails a collaborative working environment. Different from most of the other tools, the Web-based knowledge management system developed based the RFBSE model is designed to be used in the collaborative working environment. Moreover, considering the extendibility of the computer tools, the system guided by the RFBSE allows users to build firstly a systematic framework for organising design information and knowledge, within which various types of knowledge including formal and tacit knowledge can be added. Beside, details on specific knowledge element can always be added to the framework when necessary. Thus, comparing to the relative fixed representation in other tools, the Web-based knowledge management system has better extendibility.

\section{Discussion}

The core idea of this research is in capturing designers' useful knowledge and experience embedded in their mind for effective future reuse. In this case, this research has unique focus compared to other research works in three aspects.

a. Capturing design knowledge through design evolution

Evolution is regarded as a key element in the RFBSE model, which focuses on capturing and organising design knowledge generated during design changes and improvements. This kind of knowledge mainly relate to an artefact's behaviours and structure, supported by detailed analysis of related functions and requirements. Thus, the evolution element can link the other four elements together, providing useful context for the relevant design knowledge captured. A design evolution process will terminate when an optimal design has been achieved. The focus of the knowledge capture through this process is on the underlying knowledge explaining how to achieve this optimal design step by step. For each step of the evolution 
process, the granularity of knowledge representation is determined by the amount of knowwhat, know-how and know-why knowledge elements accumulated.

b. Integrating formal and informal design knowledge

The RFBSE model firstly provides a systematic structure to combine design knowledge throughout design process, in which a lot of formal design knowledge is generated. As informal design knowledge is tacit and usually exists in engineer's brains, this systematic structure can provide a useful design context in which informal knowledge can be attached to the structure. By classifying it into know-what, know-how, and know-why, the informal knowledge can be captured and integrated together with formal knowledge as external knowledge elements in the systemic structure.

\section{c. Supporting a collaborative working environment}

The RFBSE model has been implemented in a Web-based knowledge management system. This system allows engineers to easily access knowledge in a collaborative working environment. Different users can contribute to the construction of different part of the model as it is highly structured and provides clear guidance on where to attach knowledge elements. Also, multi engineers can use the system synchronously, discussing and editing the same piece of design knowledge. In this case, this system can be used to support a collaborative working environment where useful knowledge generated in the communication between design engineers, and the knowledge generated during this communication can be captured in a timely manner. People from different stages of an engineering design project can also access and benefit from the system. Sales person can contribute the information about customers' diverse requirements into the system and obtain the advantages of the design information for doing better marketing, while manufacture engineers can understand design ideas better to achieve a better production procedure as well as providing useful feedbacks to design engineers.

\section{Conclusion}

This paper proposes a RFBSE knowledge representation model which aims to capture design knowledge throughout the design process for effective reuse. The model has five key elements, i.e. requirement, function, behaviour, structure, and evolution. Among them, the function, behaviour, and structure can be regarded as basic elements in describing design objects and the design process. The requirement element is added for capturing important design knowledge and experience in the understanding of the requirements and the identification of a functional structure to fulfil the requirements. Another element, namely evolution, is also considered in the model as it tracks the design changes and more importantly the reasoning process behind these changes. The design knowledge and experience captured is useful for design reuse and affects its effectiveness. With these five elements, the RFBSE model can provides a systematic structure in capturing and organising design knowledge, and further integrates formal and informal knowledge into this structure. 
This model allows more considerations to be recorded in the design process and facilitates the capture of knowledge from the complex interpretation, transformation, decomposition and synthesis process. The evaluation of the RFBSE model in an engineering design project, together with its implementation in a Web-based knowledge management system developed based on the model, have shown that the effectiveness of the model in guiding knowledge capture and representation during engineering design process.

\section{Reference}

[1] S. K. Chandrasegaran, K. Ramani, R. D. Sriram, I. Horváth, A. Bernard, R. F. Harik, and W. Gao, "The evolution, challenges, and future of knowledge representation in product design systems,” Comput. Des., vol. 45, no. 2, pp. 204-228, 2013.

[2] R. Owen and I. Horváth, "Towards Product-Related Knowledge Asset Warehousing in Enterprises,” Proc. Fourth Int. Symp. Tools Methods Compet. Eng., pp. 155-170, 2002.

[3] J. S. Gero, “Design Prototypes - a Knowledge Representation Schema for Design,” Ai Mag., vol. 11, no. 4, pp. 26-36, 1990.

[4] B. Sembugamoorthy, V. and Chandrasekaran, Functional representation of devices and compilation of diagnostic problem-solving systems. In Experience, Memory, and Reasoning (Kolodner, J.L., \& Riesbeck, C.K., Eds.), pp. 47-73. Hillsdale, NJ: Erlbaum. 1986.

[5] Y. Iwasaki, M. Vescovi, R. Fikes, and B. Chandrasekaran, "Causal Functional Representation Language With Behavior-Based Semantics,” Appl. Artif. Intell., vol. 9, no. 1, pp. 5-31, 1995.

[6] Y. Umeda and T. Tomiyama, "FBS Modeling: Modeling Scheme of Function for Conceptual Design,” Proc. 9th Int. Work. Qual. Reason., pp. 271-278, 1995.

[7] S. R. Bhatta and A. K. Goel, "Discovery of Physical Principles from Design Experiences,” Ai Edam-Artificial Intell. Eng. Des. Anal. Manuf., vol. 8, no. 2, pp. 113123, 1994.

[8] J. S. Gero and U. Kannengiesser, "The situated function-behaviour-structure framework,” Des. Stud., vol. 25, no. 4, pp. 373-391, 2004.

[9] J. S. Gero and U. Kannengiesser, "A function-behavior-structure ontology of processes,” Ai Edam, vol. 21, no. 04, pp. 379-391, 2007.

[10] F. Christophe, A. Bernard, and E. Coatanea, "RFBS: A model for knowledge representation of conceptual design,” Cirp Ann. Technol., vol. 59, no. 1, pp. 155-158, 2010.

[11] C. C. Gu, J. Hu, Y. H. Peng, and S. Li, "FCBS model for functional knowledge representation in conceptual design,” J. Eng. Des., vol. 23, no. 8, pp. 577-596, 2012.

[12] B. Chandrasekaran and J. R. Josephson, “Function in device representation,” Eng. Comput., vol. 16, no. 3-4, pp. 162-177, 2000.

[13] Y. L. Tian, H. J. Zou, and W. Z. Guo, “An integrated knowledge representation model for the computer-aided conceptual design of mechanisms," Int. J. Adv. Manuf. Technol., vol. 28, no. 5-6, pp. 435-444, 2006. 
[14] A. K. Goel, S. Rugaber, and S. Vattam, "Structure, behavior, and function of complex systems: The structure, behavior, and function modeling language," Artif. Intell. Eng. Des. Anal. Manuf., vol. 23, no. 01, p. 23, 2009.

[15] J. Ma, J. Hu, K. Zheng, and Y. Peng, "Knowledge-based functional conceptual design : Model , representation , and implementation,” Concurr. Eng. Res. Appl., vol. 21, no. 2, pp. 103-120, 2013.

[16] J. S. Liang, "The methodology of knowledge acquisition and modeling for troubleshooting in automotive braking system," Robot. Comput. Integr. Manuf., vol. 28, pp. 24-34, 2012.

[17] Y. Nomaguchi and K. Fujita, "Knowledge representation framework for interactive capture and management of reflection process in product concepts development," Adv. Eng. Informatics, vol. 27, pp. 537-554, 2013.

[18] T. Tomiyama, T. J. Van Beek, A. Alberto, A. Cabrera, H. Komoto, and V. D. Amelio, "Making function modeling practically usable," Artif. Intell. Eng. Des. Anal. Manuf., no. Special Issue 03, pp. 301-309, 2013.

[19] N. Crilly, "Function propagation through nested systems,” Des. Stud., vol. 34, pp. 216-242, 2013.

[20] M. Aurisicchio, R. Bracewell, and G. Armstrong, "The function analysis diagram: Intended benefits and coexistence with other functional models,” Artif. Intell. Eng. Des. Anal. Manuf., vol. 27, no. 3, pp. 249 - 257, 2013.

[21] D. Baxter, J. Gao, K. Case, J. Harding, B. Young, S. Cochrane, and S. Dani, “A framework to integrate design knowledge reuse and requirements management in engineering design,” Robot. Comput. Integr. Manuf., vol. 24, no. 4, pp. 585-593, 2008.

[22] G. Pahl, W. Beitz, J. Feldhusen, and K.-H. Grote, Engineering design: a systematic approach, no. 2. 2007.

[23] R. Bracewell, K. Wallace, M. Moss, and D. Knott, “Capturing design rationale,” Comput. Des., vol. 41, no. 3, pp. 173-186, 2009.

\section{Acknowledgement}

Acknowledgement is given to University of Portsmouth for the financial support for this research. Acknowledgement is also given to the members of Formula Student project team in University of Portsmouth for their helps in this research. 